\title{
İlkokul 4. Sınıf Öğrencileri için Bütünleşme Ölçeğinin Geliştirilmesi*
}

\section{Deniz GÖKÇE ERBILL ** Ayfer KOCABAŞ ***}

Öz: Grup çalışması süreci içerisinde, grup üyelerinin birbirleriyle yardımlaşması ve grubun başarıya ulaşması için gösterdikleri çaba olarak tanımlanabilecek bütünleşme, işbirlikli öğrenme yönteminin, akademik başarı üzerinde ortaya çıkardığı olumlu etkiyi açıklamada en önemli değişkenlerden biri bütünleşmedir. Bu araştırmada ilkokul dördüncü sınıf düzeyinde gerçekleştirilen işbirlikli öğrenme çalışmalarında, yöntemin başarıyı nasıl etkilediğini ortaya çıkarmak amacıyla gelecekteki araştırmalarda kullanılacak bir bütünleşme ölçeği geliştirilmesi amaçlanmıştır. Alan yazın taraması, öğrencilerle yapılan görüşmeler ve daha önce yurtdışında geliştirilen ölçekler 1şığında 22 madde beşli likert tipinde hazırlanmıştır ve uzman görüşüne sunulmuştur. Ölçeğin geçerlik ve güvenirlik İzmir ilinde öğrenim görmekte olan 242 ilkokul 4. sınıf öğrencisi ile gerçekleştirilmiştir. Güvenirlik analizi amacıyla Cronbach’s Alpha güvenirlik katsayısı, madde ayırt-edicilikleri ve madde toplam puan korelasyonları belirlenerek değerlendirilmiştir. Geçerlik analizleri için açımlayıcı ve doğrulayıcı faktör analizi gerçekleştirilmiştir. Yapılan analizler sonucunda, görev bütünleşmesi ve sosyal bütünleşme alt boyutlarından oluşan ve 15 maddeden oluşan ölçme aracının yapısı doğrulanmıştır.

Anahtar Kelimeler: Bütünleşme, işbirlikli öğrenme, ölçek geliştirme

\section{Development of Cohesion Scale for 4th Grade Elementary School Students}

Abstract: Cohesion is one of the most important variables explaining the positive effect of cooperative learning on academic achievement. In this study, it is aimed to develop a cohesion scale for further studies in order to determine how this method effect success in the cooperative learning studies at fourth grade primary school level. According to a literature survey, a review of the developed scales in other countries and the interviews with students, 22 items were prepared in 5-point Likert type and reviewed by experts. The validity and reliability study of the scale was carried out with 242 fourth grade primary school students in İzmir. Cronbach's Alpha reliability coefficient, item discrimination values and item-total correlation values were calculated and evaluated for the reliability analysis. For validity analysis, exploratory and confirmatory factor analyses were performed. As a result of the

\footnotetext{
${ }^{*} \mathrm{Bu}$ çalışma birinci yazarın, ikinci yazar danışmanlığında tamamladığı doktora tezinin bir bölümüdür.

**Araş. Gör. Dr, Karamanoğlu Mehmetbey Üniversitesi, Eğitim Fakültesi, Temel Eğitim Bölümü, Email:dgerbil@kmu.edu.tr Orcid No: https://orcid.org/0000-0001-7893-7993
}

****Profesör Dr, Dokuz Eylül Üniversitesi, Buca Eğitim Fakültesi, Temel Eğitim Bölümü Email: ayfer.kocabas@deu.edu.tr, Orcid No: https://orcid.org/0000-0002-5566-212X 
performed analyses the structure of the 15-item scale, consists of task cohesion and social cohesion sub-dimensions, was confirmed.

Keywords: cohesion, cooperative learning, scale development

\section{Giriş}

İşbirlikli öğrenme yönteminin etkililiği üzerine uzun süredir gerçekleştirilen çalışmalar sonucunda, bu öğretim yönteminin başta akademik başarı olmak üzere pek çok psiko-sosyal değişken üzerinde olumlu etkisi ortaya konulmuştur. Bu olumlu etkinin nasıl ortaya çıktığı ile ilgili çeşitli görüşler öne sürülmüştür. Slavin'in (2015) öne sürmüş olduğu modelde, bütünleşme (cohesion) kavramı (Şekil 1), işbirlikli öğrenme yönteminin akademik başarıyı geliştirilmesinde önemli bir role sahiptir. Bu önem doğrultusunda, öğrencilerin bütünleşme becerilerinin zaman içerisinde uygulanan öğretim yöntemine bağlı olarak nasıl geliştiğinin ve bu gelişmenin akademik başarıyı nasıl etkilediğinin ortaya konulması gerekmektedir.

Bütünleşme kavramı üzerine farklı tanımlar yapılmıştır. $\mathrm{Bu}$ tanımlamalardan en önemlilerinden birini yapan Festinger’e (1950) göre bütünleşme, tüm grup üyelerinin grup için harcadıkları tüm çabanın sonucudur ve üyelerin grupta kalmasına gerekçe olacak güç alanıdır (Festinger, Schachter ve Back, 1950). Bir diğer tanımda bütünleşme, grubun yıkıcı güçlere karşı direncidir (Gross ve Martin, 1952). Daha ilerleyen yıllarda ise bir grubu ortak amaç ve hedefler doğrultusunda bir araya getiren ve birlik olarak kalmasını sağlayan dinamik bir süreç olarak tanımlanmıştır (Carron, 1982). Bütünleşme üzerine yapılan tanımlar ve çalışmalar incelendiğinde (Festinger, 1950; Festinger, Schachter ve Back, 1950; Gross ve Martin, 1952; Carron, 1982), sadece eğitim bilimlerinde kullanılan küçük gruplardan ziyade, spor takımları, askeri çalışmalar ve sosyal psikoloji alanında yapılan çalışmaları ve bu çalışmalardaki küçük grupları kapsadığı da görülmektedir. Eğitim bilimleri alanında ise kavram; grup üyelerinin diğer grup üyelerine, kendi gruplarını önemsedikleri için yardım etmesi olarak da tanımlanmaktadır (Slavin, 2015). Bu tanım bütünleşme kavramını sadece sosyal bütünleşme adı altında ele almıştır.

Bütünleşme üzerine yapılan araştırmalar sonucunda bütünleşmenin, sosyal bütünleşme ve görev bütünleşmesi olarak iki yapının bileşimi olduğu ortaya çıkmıştır (Carless ve DePaola, 2000; Van den Bossche, Gijselaers, Segers ve Kirschner, 2006). Mullen ve Copper'a (1994) 
göre görev bütünleşmesi, bir amaca ulaşmak için gerçekleştirilen grup çalışmasındaki paylaşımdır. Sosyal bütünleşme ise grup üyeleri arasındaki arkadaşlık, sevgi, yakınlık gibi doğal duygulardır.

İşbirlikli öğrenme gruplarında öğrenciler küçük gruplarda bir arada çalışırlar. Öğrencileri bir araya gelmeye zorlayan konu başarıdır. Bu başarı bireysel bir başarıdır fakat grup olarak başarıya sıkı sıkıya bağlıdır. Çünkü yöntemin doğası gereği grup bir bütün olarak başarıya ulaşmadan, bireyler başarılı olarak kabul edilemezler (Slavin, 2015; Sharan ve Sharan, 1992). Slavin (2015) işbirlikli öğrenme yönteminin, ilkokul öğrencilerinin akademik başarı düzeylerini nasıl etkilediğine dair bir model önerisinde bulunmuştur (Şekil 1.) Bu modele göre, öğrenciler işbirlikli öğrenme gruplarında ortak amaçlar doğrultusunda bir araya gelir. Ortak grup amaçları, öğrencilerin gruba yönelik sosyal bütünleşme düzeylerini geliştirir. Ortak grup amaçları ve sosyal bütünleşme ile motivasyon ve akran ilişkileri arasında çift yönlü bir ilişki bulunmaktadır. Değişkenler arasındaki bu etkileşim de akademik başarı üzerinde olumlu etkinin ortaya çıkmasına neden olur.

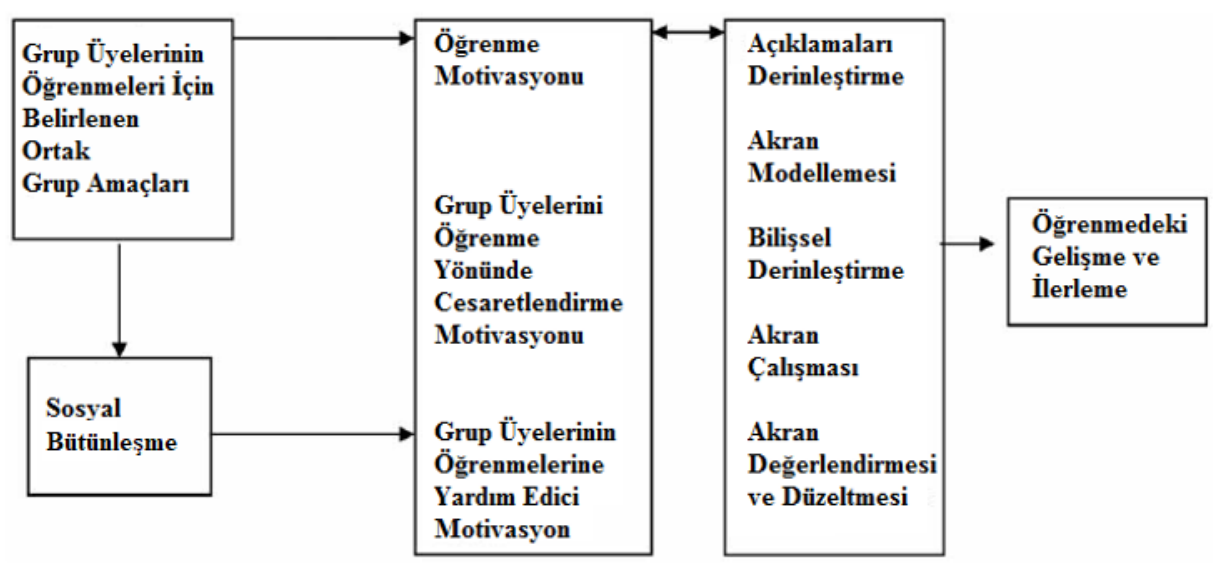

Şekil 1. İşbirlikli öğrenmenin başarıyı nasıl etkilediğine dair model (Slavin, 2015'ten uyarlanmıştır.)

\section{İşbirlikli Öğrenme ve Bütünleşme}

İşbirlikli öğrenme grubunun başarısında en önemli faktörlerden biri grubun bütünleşmesidir. Grup içerisinde gerçekleşen etkileşimlerin kalitesi, grubun bütünleşme düzeyi ile ilişkilidir. Grup bütünleşmesi temel olarak öğrencilerin grup içerisinde yapılacak işleri daha iyi yapmalarını sağlar. Çünkü öğrenci, kendini grubun bir parçası olarak görür ve her bir grup 
üyesinin de başarılı olmasını ister. Sosyal bütünleşme teorisi işbirlikli öğrenme yönteminin ve öğrenci başarısının grup etkileşimlerine bağlı olduğunu savunur (Battistich, Solomon ve Delucchi, 1993). Akademik başarının, sosyal bütünleşme ve grup içerisindeki etkileşimlerin kalitesine bağlı olduğu sonucu bazı araştırmalarca (Slavin, 1995; Prien, 2001) da desteklenmektedir.

Geliştirilen çeşitli işbirlikli öğrenme tekniklerinde sosyal bütünleşme kavramına önem verilmiş ve bu kavram temel alınarak teknikler geliştirilmiştir. Cohen (1994), Sharan ve Sharan (1992) ve Aronson, Bridgeman ve Geffner (1978) tarafindan geliştirilen işbirlikli öğrenme tekniklerinde kullanılan "görevde uzmanlaşma"nın amacı öğrenciler arasında bütünleşme yaratmaktır. Johnson ve Johnson (2008) tekniklerinde bu bütünleşme temel olarak öğrencilerin farklı rollere atanması ve bu görevlerde uzmanlaşması aracılığı ile gerçekleşir. Bu tekniklerin bir sonucu olarak, işbirlikli öğrenme sürecinde eğer öğrenciler grup arkadaşlarına değer verirlerse (işbirlikli öğrenme öncesi hazırlık ve grup bütünleşmesi çalışmaları sonucunda) ve her bir grup üyesi diğer bir grup üyesine bağlı olursa, öğrenciler diğer arkadaşlarının başarılı olması için daha çok çaba göstereceklerdir. Bir diğer ifadeyle, işbirlikli öğrenme yöntemi öğrencilerin gruba yönelik bütünleşmelerini artırır, bu artış da grup üyelerinin performansını yükseltir (Chang ve Bordia, 2001).

Johnson ve Johnson (1998) geliştirdikleri birlikte öğrenme tekniğinde gruba bir kimlik kazandırarak grup üyelerinin birbirleriyle ve gruplarıyla olan bütünleşmelerini artırmayı amaçlamışlardır. $\mathrm{Bu}$ amaç doğrultusunda; tekniğin uygulanışında her bir grup kendine grup ismi, grup sloganı, grup rolleri belirlerler ve bu sayede her bir grup üyesinin grubuyla bütünleşmesi kolaylaşır. Bütünleşme sonucunda da öğrenciler grubunun başarısının grup arkadaşlarının başarısına bağlı olduğunu bilir ve her bir grup arkadaşının başarılı olması için elinden gelen çabayı gösterir.

Gillies (2004) de bütünleşme kavramını takım inşa edici aktiviteler açısından ele almıştır ve grup bütünleşmesinde sosyal becerilerin önemine atıf yapmıştır. Ona göre, sosyal becerilerin geliştirilmesi kişilerarası becerilerin geliştirilmesine bağlıdır. Aktif dinleme, görüşünü özgürce açıklama, kendi davranışının sorumluluğunu üstlenme gibi kişilerarası becerilerin gelişimi; kendi sırasını bekleme, görev paylaşımı yapma, diğer insanların görüşlerini dinleme ve anlamaya çalışma, karar verirken demokratik olma ve farklılıkları 
algılama gibi küçük grup becerilerini de geliştirmektedir. Webb’e (2008) göre bu becerilerin gelişimi ve kullanılması, grup üyelerinin birbirlerine güvenmelerini, kabul etmelerini ve desteklemelerini sağlamaktadır. Bu yolla olumlu ve etkili bir iletişim gerçekleştirilerek çatışmalar da kolayca çözülebilmektedir. Gillies (2004) ve Webb'in (2008) bu görüşleri işbirlikli öğrenmenin bütünleşmeyi nasıl sağladığı noktasında önemli ayrıntılar sunmaktadır. İşbirlikli öğrenme yönteminin başarısı, aynı zamanda grup üyelerinin nasıl bütünleştiği ile de doğru orantılıdır.

\section{İşbirlikli Öğrenmede Bütünleşmenin Rolü}

Battisch ve diğerlerinin (1993) gerçekleştirdiği araştırmada işbirlikli öğrenme yönteminin uygulandığı gruplarda öğrenci başarısının, kaliteli grup içi etkileşimlere ve sosyal bütünleşmeye bağlı olduğu sonucuna ulaşılmıştır. Kaliteli grup içi etkileşimler, öğrencilerin birbirlerine grup içerisinde dostça yaklaşması, birbirlerine yardım etmeleri, grup arkadaşının başarısını önemsemesi ve işbirliği içerisinde çalışmasını kapsamaktadır.

İşbirlikli öğrenme tekniklerinin öğrenci başarısı üzerindeki etkisi büyüktür. Bu etkide bütünleşme düzeylerinde meydana gelen değişimin de etkisi bulunmaktadır. Örneğin Slavin’e (1995) göre birleştirme tekniğinin öğrenci başarısı üzerindeki etkisi net değildir. Bu teknikteki temel problem ise grup üyelerinin öğrenmelerinin diğer grup üyelerinin kendi sorumluluğundaki parçaları iyi öğrenmelerine bağlı olmasıdır. Dolayısıyla bir grup üyesi kendi bölümünü iyi bir şekilde öğrenemezse arkadaşlarına da iyi öğretemez ve başarı tam anlamıyla sağlanamaz.

Birleştirme tekniğinin aksine grup araştırması tekniği ise akademik başarı üzerinde olumlu etki sağlamaktadır (Sharan ve Shachar, 1988). Teknik doğası gereği grup içerisinde bütünleştirmenin önemine atıf yapmakta ve grubun başarısının aynı zamanda bireylerin başarısına bağlı olduğunu vurgulamaktadır (Sharan ve Sharan, 1990).

Son olarak Johnson ve Johnson'un (2008) gerçekleştirdiği çalışmada işbirlikli öğrenme yönteminin başarısının grup ödüllerine bağlı olduğu sonucuna ulaşılmıştır. Grup ödülünün sürece dâhil edilmesi öğrencilerin bütünleşme düzeylerini artırmakta ve bunun sonucunda da başarıda olumlu yönde bir farklılaşma meydana gelmektedir. Bu bulguları Mattingly ve van Sickle'nin (1991) yapmış olduğu araştırma sonuçları da desteklemektedir. Birleştirme II tekniğinin kullanıldığı bu araştırmada işbirlikli öğrenme yönteminin öğrenci başarısı üzerindeki 
etkisinin doğrudan ortak bir amaç ve ödüle bağlı olduğunu ve yöntemin başarısı için öğrencilerin bireysel katkılarının mutlaka değerlendirmesi gerektiğini vurgulamışlardır.

Yapılan araştırmalar göstermektedir ki, işbirlikli öğrenme yönteminin başarıya ulaşması için grup üyelerinin gruplarıyla olan bütünleşmeleri oldukça önemlidir. Grup üyeleri ortak bir amaç ve ödül için çalışırken, her bir öğrenci grubun başarısının kendi başarısına bağlı olduğunu bilmeli ve aynı zamanda grubun başarısı için diğer arkadaşlarına da yardım etmelidir. İşbirlikli öğrenme süreci içerisinde grup çalışması değerlendirilirken bireysel çalışmalar ve bireyin grubuna yaptığı katkı da mutlaka değerlendirilmelidir. Diğer yandan grubun başarı odaklı çalışma sürecinde kişilerarası ve küçük grup becerilerinin geliştirilmesi, grubun daha etkili çalışmasını sağlayacaktır. Dolayısıyla yöntemin başarıya ulaşması için yalnızca akademik amaçlar ve çalışmalar yeterli olmamakla birlikte kişilerarası ve küçük grup becerilerinin de geliştirilmesine ihtiyaç duyulmaktadır.

\section{Araştırmanın Amacı}

İşbirlikli öğrenme yönteminin akademik başarı ve psiko-sosyal değişkenler üzerinde meydana getirdiği olumlu etkiyi kanıtlayan araştırma birikimi mevcut olsa da (Johnson, Johnson ve Stanne, 2000; Tarım, 2003; Hattie, 2009; Kyndt ve diğerleri, 2013; Kocabaş, Aş1k, Karaşahin, Erbil ve Erdoğan, 2015; Dirlikli, Aydın ve Akgün 2016; Erbil ve Kocabaş, 2018), özellikle başarıdaki olumlu etkiyi nasıl ve hangi değişkenleri işe koşarak yaptığı konusunda yeterli sayıda araştırma bulunmamaktadır (Slavin, 2015). Bu araştırmada işbirlikli öğrenmenin başarı üzerindeki değişimine sebep olan temel değişkenlerden bütünleşme üzerine bir ölçek geliştirilmesi amaçlanmıştır.

\section{Yöntem}

Araştırmanın bu bölümünde ölçeğin geliştirilme süreci, çalışma grubu ve verilerin analizine ilişkin bilgiler verilecektir.

\section{Ölçek Maddelerinin Hazırlanma Süreci}

Ölçeğin geliştirilmesine kapsamlı bir alan yazın taraması ile başlanmıştır. Bütünleşme üzerine yapılan araştırmalar incelenmiştir ve bütünleşmenin nasıl bir psikolojik yapı olduğu 
ortaya konulmaya çalışılmıştır. Bütünleşme üzerine yapılan çalışmalarda Türkiye'de ve ilkokul 4. sınıf düzeyinde kavramın incelenmesine ihtiyaç duyulmuş ve 32 ilkokul 4. sınıf öğrencisinin grup çalışmasına ilişkin görüşleri 2 soruluk bir yapılandırılmış görüşme formu ile alınmıştır. $\mathrm{Bu}$ görüşme formunda öğrencilere "Yaptığınız grup çalışmalarını düşünün. Grup arkadaşlarınızla ilişkilerinizi nasıl tanımlarsınız?”, “Yaptı̆̆ınız grup çalışmalarını düşünün. Grup içerisinde görevlerinizi nasıl yerine getirirsiniz?”, “Arkadaşlarınız görevlerini nasıl yerine getirir?”, "Başarılı olmak için grubun nasıl çalışması gerekir?” soruları yöneltilmiştir. Nitel sorular analiz edilerek öğrencilerin grup çalışmalarındaki arkadaşlık ilişkilerini nasıl değerlendirdikleri, grup içi görevleri nasıl yerine getirdiklerinden hareketle grup çalışmasındaki tutum ve davranışları ortaya konulmaya çalışılmıştır.

Madde yazımından önce alanyazında var olan ölçekler incelenmiştir ve madde yazımında yararlanılmıştır (Martin, Carron, Eys ve Loughead, 2012; Carless ve De Paola, 2000; Sargent ve Sue Chan, 2001). Alanyazın taraması, öğrencilerle yapılan görüşmeler, daha önce yurtdışında geliştirilen ölçekler ışı̆̆ında madde yazımına geçilmiştir. Madde yazımında öğrencilerin yaş grubu özellikleri dikkate alınmıştır ( 9 yaş).

Geliştirilen 22 maddelik bütünleşme ölçeğinin taslak formu 5'li likert tipinde bir dereceleme ölçeği şeklinde yapılandırılmıştır. Olumsuz (ters) madde kullanılmamıştır. Ölçeğin taslak formu kapsam geçerliği açısından 2 program geliştirme uzmanı, 1 spor bilimleri uzmanı ve 2 Türkçe öğretimi uzmanına sunulmuş olup alınan görüşler doğrultusunda yazım ve anlam ile ilgili hatalar düzeltilmiştir.

Ölçeğin geçerlik güvenirlik çalışmaları, İzmir ilinde öğrenim görmekte olan 242 ilkokul 4. sınıf öğrencisi ile gerçekleştirilmiştir. Ölçek geliştirme çalışmalarında, örneklem büyüklüğünün madde sayısının 5 ile 10 katı arasında olması önerilmektedir (Şencan, 2005). Çalışma grubu seçimi, uygun örnekleme yöntemi ile yapılmıştır. Uygun örnekleme yönteminde, araştırmacı ihtiyacı dahilinde ulaşmak istediği büyüklükteki gruba ulaşana kadar, kolay bir şekilde ulaşabildiği, ulaşılabilirliği en kolay ve az maliyetli gruplarla çalışır (Büyüköztürk, Kılıç Çakmak, Akgün, Karadeniz ve Demirel; 2014). Bu araştırmada ilkokul dördüncü sınıf öğrencileri araştırmanın hedef grubu olarak belirlenmiştir. İzmir ve Karaman illerinde ulaşılabilirlik ve en düşük maliyet şartları göz önünde bulundurularak çalışma grubu oluşturulmuştur. 


\section{Uygulama Süreci}

Ölçeğin uygulama süreci, ilkokul 4. sınıf sosyal bilgiler dersinde gerçekleştirilmiştir. Ölçeğin yanıtlanması için yaklaşık 30 dakika süre verilmiştir ve çalışma grubunun yaş/gelişim özellikleri dikkate alınarak, her bir madde teker teker okunmuştur ve öğrencilerin anlamakta zorlandığı yerler ayrıntılı bir şekilde açıklanmıştır. Öğrencilerin cevaplama sürecinde, daha önce yaptıkları grup çalışmaları ve işbirlikli öğrenme faaliyetlerini düşünmeleri istenmiş; küçük grup çalışmalarına yönelik olarak önceki deneyimlerini düşünerek ölçek maddelerini yanıtlamaları beklenmiştir.

\section{Verilerin Analizi}

Güvenirlik analizi amacıyla madde toplam puan korelasyonları, madde ayırt edicilikleri ve Cronbach's Alpha güvenirlik katsayısı belirlenerek değerlendirilmiştir. Geçerlik analizlerine açımlayıcı faktör analizi (AFA) ile başlanmıştır. Alanyazında geliştirilen ölçeklerin iki faktörden oluştuğu görülmüştür. Bu noktada, yapıdan emin olunduğu durumlar için, AFA yerine doğrudan DFA da yapılması araştırmacılar tarafından önerilebilmektedir (Can, 2016; Hurley ve diğerleri, 1997). Fakat ölçme aracının Türk kültüründe ilk defa geliştiriliyor olması ve ilkokul yaş grubu özelliklerinin değişkenlik meydana getirebilme riskleri nedeniyle yine de AFA gerçekleştirilmiştir. Ölçeğin faktör analizi işlemlerine uygun olup olmadığını ortaya koymak için Kaiser Mayer Olkin (KMO) ve Barletttestleri kullanılmıştır. Arkasından madde analizi yapılmıştır. Ölçeğin yapı geçerliğini tespit etmek amacıyla doğrulayıcı faktör analizine (DFA) geçilmiştir. DFA'da uyum indeksleri ve yol analizden yararlanılmıştır.

\section{Bulgular}

$\mathrm{Bu}$ bölümde ölçeğin uygulama sürecinin arkasından elde edilen verilerin analizi sonucunda elde edilen bulgulara yer verilmiştir. Bulguları iki alt boyutta incelemek mümkündür. Bunlardan ilki açımlayıcı faktör analizine (AFA) ilişkin bulgular, diğeri ise doğrulayıcı faktör analizine (DFA) ilişkin bulgulardır.

\section{Açımlayıcı Faktör Analizine İlişkin Bulgular}

Ölçeğin yapılandırılması için faktör analizi çalışmalarına Kaiser Mayer Olkin (KMO) ve Barlett testleri kullanılarak başlanmıştır. KMO değeri 1'e yakın olarak bulunmuştur ve bu sonuç örneklem sayısının belirlenen analiz yöntemine uygun olduğunu göstermektedir (Can, 2016). Diğer yandan Barlett Testi anlamlı sonuç vermiştir $(\chi 2=1378.344 ; p<.000)$. Bu sonuç 
YYÜ Eğitim Fakültesi Dergisi (YYU Journal of Education Faculty), 2020; 17(1):700-721, http://efdergi.yyu.edu.tr,

verilerin normal bir dağılım gösterdiğini belirtmektedir (Büyüköztürk, 2013). Arkasından madde analizi gerçekleştirilmiştir ve analiz sonuçları Tablo 1'de sunulmuştur:

Tablo 1. Döndürülmüş̧ temel bileşenler analizi sonuçları

\begin{tabular}{|c|c|c|c|}
\hline \multirow[t]{2}{*}{ Madde Numarası } & \multirow{2}{*}{$\begin{array}{l}\text { Ortak } \\
\text { Faktör } \\
\text { Varyansı }\end{array}$} & \multicolumn{2}{|c|}{ Döndürme Sonrası } \\
\hline & & 1. Faktörde Yükü & 2. Faktörde Yükü \\
\hline B7 & 0.541 & 0.722 & \\
\hline B2 & 0.502 & 0.701 & \\
\hline $\mathrm{B} 10$ & 0.459 & 0.675 & \\
\hline B8 & 0.442 & 0.595 & \\
\hline B4 & 0.348 & 0.555 & \\
\hline B9 & 0.330 & 0.551 & \\
\hline B11 & 0.352 & 0.511 & \\
\hline B6 & 0.257 & 0.417 & \\
\hline B21 & 0.544 & & 0.734 \\
\hline B18 & 0.505 & & 0.690 \\
\hline B22 & 0.438 & & 0.606 \\
\hline B20 & 0.528 & & 0.589 \\
\hline B16 & 0.429 & & 0.584 \\
\hline B13 & 0.334 & & 0.528 \\
\hline $\mathrm{B} 15$ & 0.440 & & 0.371 \\
\hline
\end{tabular}

Madde analizi sonucunda düşük faktör yük değerine sahip 7 madde ölçekten çıkarılmıştır. Ortaya çıkan ölçek iki faktörlüdür. İlk faktör görev bütünleşmesi olarak isimlendirilmiştir. Bu faktör toplam varyansın \%34'ünü açıklamaktadır. İkinci faktör ise sosyal bütünleşme olarak isimlendirilmiştir. Bu faktör toplam varyansın \%9'unu açıklamaktadır. İki faktörün birlikte açıkladıkları toplam varyans \%43’tür.

AFA sonucunda iki faktörlü bir yapı bulunmuştur. Bu bulgu alanyazındaki diğer ölçek geliştirme çalışmaları ile uyumludur (Martin ve diğerleri, 2012; Carless ve De Paola, 2000; Sargent ve Sue Chan, 2001). Bütünleşme, sosyal bütünleşme (7 madde) ve grup bütünleşmesi ( 8 madde) olarak iki alt bileşenden meydana gelmektedir.

\section{Doğrulayıcı Faktör Analizine İlişkin Bulgular}

AFA ile yapılandırılan ölçme aracının doğruluğunun sınanması amacıyla doğrulayıcı faktör analizine (DFA) geçilmiştir (Şekil 2). DFA sonuçları incelendiğinde (Tablo 2), $\chi^{2} /$ sd değeri 1.555 olarak bulunmuştur. Bu değerin 3'ten düşük olması, RMSEA değerinin 0.05 olarak 
YYÜ Eğitim Fakültesi Dergisi (YYU Journal of Education Faculty), 2020; 17(1):700-721, http://efdergi.yyu.edu.tr,

kabul edilen mükemmel uyum değerinden küçük olarak 0.048 olarak bulunması, AGFI ve GFI indekslerinin 0.90 üzerinde olması kabul edilebilir olarak değerlendirilmektedir (Marsh ve Grayson, 1995; Schumacker ve Lomax, 1996). NNFI ve CFI değerlerinin de 0.95'in üzerinde bulunması; tüm değerler üzerinden incelendiğinde ölçme aracının mükemmel uyum özelliği taşıdığını göstermektedir (Jöreskog ve Sörböm, 1993; Sümer, 2000; Çokluk, Şekercioğlu ve Büyüköztürk, 2012).

Tablo 2. DFA uyum indeksi değerleri

\begin{tabular}{ll}
\hline Uyum İndeksleri & Uyum Değerleri \\
\hline$\chi^{2} /$ df & 1.555 \\
RMSEA & 0.048 \\
SRMR & 0.0518 \\
GFI & 0.925 \\
AGFI & 0.899 \\
CFI & 0.977 \\
NNFI & 0.972 \\
\hline
\end{tabular}

DFA analizi sonucunda iki faktörlü yapı doğrulanmıştır. Ölçek 2 faktörlü 15 maddeden oluşan bir yapıdadır.

Güvenirlik analizi amacıyla Cronbach's Alpha güvenirlik katsayısı, madde ayırtedicilikleri ve madde toplam puan korelasyonları belirlenerek değerlendirilmiştir. Düzeltilmiş madde toplam korelasyon katsayısı 0.3 üzeri iyi, 0.2 üzeri zorunlu ise alınabilir, 0.2 altı ise çıkarılmalı olarak belirtilmektedir (Büyüköztürk, 2013). Ölçek maddeleri incelendiğinde 0.2 ve 0.3 arasında 2 madde olduğu görülmektedir. Alt ve üst \%27'lik gruplarda tüm maddeler arasında anlamlı farklılık bulunmaktadır. Cronbach's Alpha değerlerine bakıldığında, görev bütünleşmesi faktörünün güvenirlik değeri 0.788 , sosyal bütünleşme faktörünün güvenirlik değeri 0.777 'dir.Ölçeğin tümü için güvenirlik değeri 0.859 'dur. 


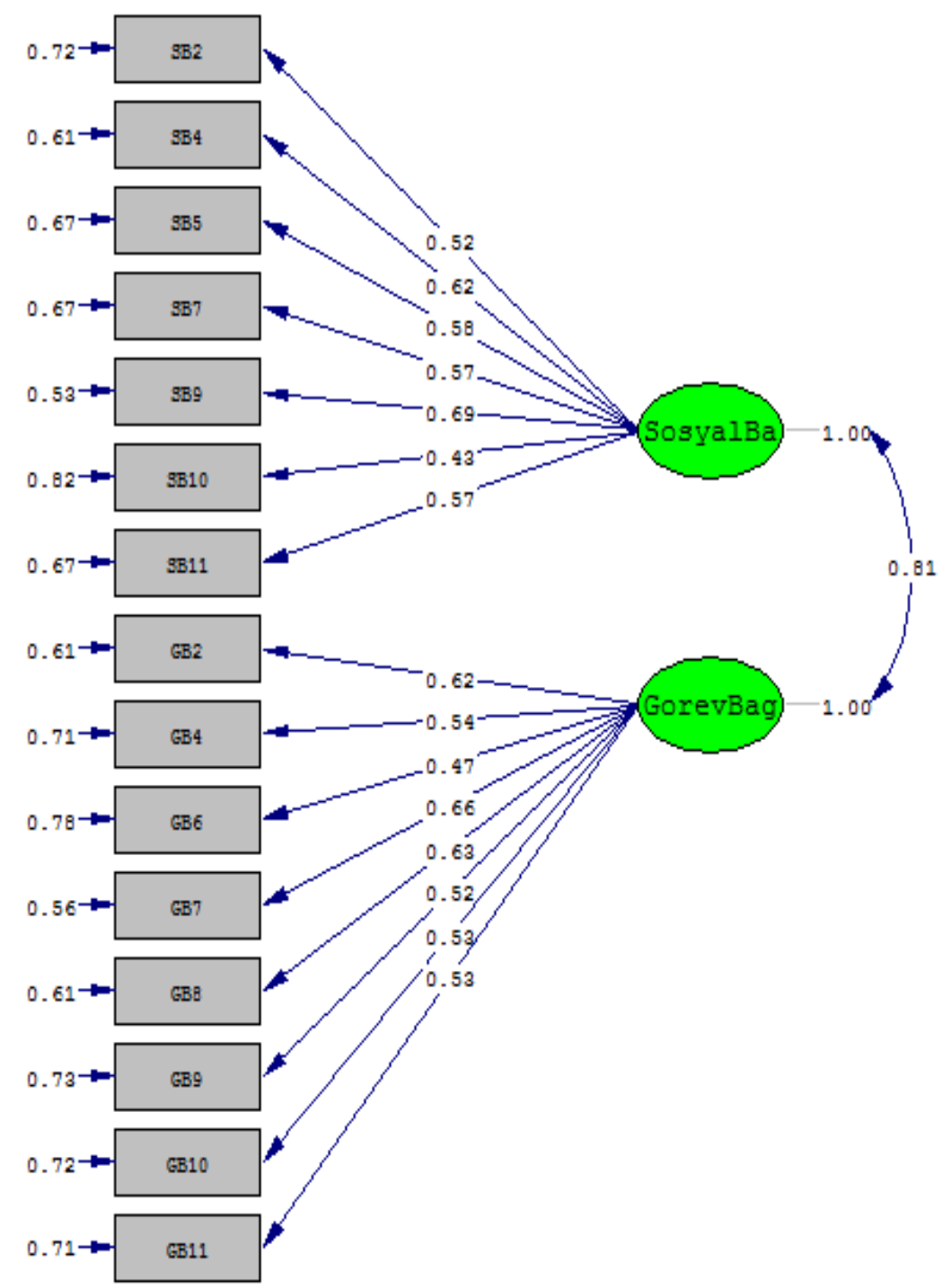

Chi-8quare $=138.41, d f=89, p-v a l u e=0.00062$, RMSEA $=0.048$

Şekil 2. Gizil değişken ile gözlenen değişkenler arasındaki ilişkileri ve gözlenen değişkenlerin hata varyansları

Toplam puanlar ve alt faktör puanları arasındaki ilişki incelendiğinde, sosyal bütünleşme ve görev bütünleşmesi arasında 0.610, sosyal bütünleşme ile toplam puan arasında 0.880, görev bütünleşmesi ile toplam puan arasında 0.913 değerlerinde pozitif yönde ve anlamlı bir ilişki $(\mathrm{p}<0.01)$ olduğu görülmektedir. Buradan hareketle tüm alt boyutların hem birbiriyle hem de toplam puanla arasında pozitif yönde ve istatistiksel olarak anlamlı bir ilişki $(p<0.01)$ içerisinde olduğu yorumu yapılabilir. Ölçeğin herhangi bir alt faktöründe yüksek bir puan alan 
öğrencinin, diğer alt faktörlerde de yüksek puan alması oldukça olasıdır. Geliştirilen ölçeğin maddeleri Ek 1'de verilmiştir.

\section{Tartışma ve Sonuç}

İşbirlikli öğrenmenin başarı ve diğer psiko-sosyal değişkenler üzerinde meydana getirdiği olumlu yönde değişimin temel nedeni bütünleşmedir (Slavin, 2015). Bu araştırmada ilkokul 4. sınıf düzeyinde bir Bütünleşme Ölçeği geliştirilerek gelecek araştırmalara kaynaklık etmesi ve işbirlikli öğrenme yönteminin öğrencilerde meydana getirdiği değişimin daha iyi ve net bir şekilde ortaya konulması amaçlanmıştır.

Ölçek çalışmalarına başlarken, ilkokul dördüncü sınıf öğrencilerine yaptıkları grup çalışmaları üzerine yapılandırılmış bir form ile sorular yöneltilmiştir. $\mathrm{Bu}$ sorular temelde bütünleşme kavramına atıf yapmakta olup, elde edilen sonuçlar 1şığında madde yazımına geçilmiştir. Geliştirilen 22 maddelik bütünleşme ölçeğinin taslak formu 5'li likert tipinde bir dereceleme ölçeği şeklinde yapılandırılmıştır. Ölçekte olumsuz madde yer almamaktadır. Taslak form, kapsam geçerliği açısından beş adet alan uzmanına sunulmuştur ve gelen öneriler doğrultusunda maddelerde düzenlemeler yapılmıştır. 242 öğrenciye uygulanan ölçeğin yapısının oluşturulmasında AFA ve DFA yapılmıştır. AFA sonucunda bulunan iki faktörlü yapı, sosyal bütünleşme ve görev bütünleşmesi, DFA sonucunda doğrulanmıştır. Ulaşılan bu sonuç, alanyazındaki diğer ölçme araçlarının ulaştığı sonuçlar ile uyum göstermektedir (Martin ve diğerleri, 2012; Carless ve De Paola, 2000; Sargent ve Sue Chan, 2001). Güvenirlik analizi amacıyla Cronbach's Alpha güvenirlik katsayısı, madde ayırt-edicilikleri ve madde toplam puan korelasyonları belirlenerek değerlendirilmiştir ve tüm sonuçlar ölçeğin güvenilir bir yapıda olduğunu göstermektedir. Aynı zamanda ölçeğin alt boyutları birbirleri ve toplam puan ile pozitif yönde ve istatistiksel olarak anlamlı bir ilişki içerisindedir.

Sonuç olarak Bütünleşme Ölçeği, 5'li likert tipinde ve 15 maddeden oluşmaktadır. Ölçek, sosyal bütünleşme ve görev bütünleşmesi olmak üzere iki alt boyuttan oluşmaktadır. Ölçeğe ilişkin; ölçekten alınan puan yükseldikçe, öğrencinin daha yüksek bütünleşme düzeyine sahip olduğu yorumu yapılabilir.

\section{Öneriler}


Geliştirilen ölçme aracı ilkokul 4. sınıf düzeyinde geliştirilmiştir. İlkokul kademesinin farklı kademelerinde de ölçeğin geçerlik-güvenirlik çalışmalarının yapılması önerilmektedir. İşbirlikli öğrenme yönteminin kullanıldığı deneysel ve karma desenli çalışmalarda ölçme aracının kullanılması önerilmektedir. Süreç içerisinde öğrencilerin bütünleşme düzeylerinin nasıl değiştiğinin ve bütünleşmenin motivasyon-akran ilişkileri gibi diğer değişkenlerle olan ilişkisinin akademik başarıyı nasıl etkilediği üzerine gerçekleştirilecek çalışmalara ihtiyaç duyulmaktadır.

\section{Makalenin Bilimdeki Konumu}

Sınıf Eğitimi / Eğitim Bilimleri

\section{Makalenin Bilimdeki Özgünlüğü}

Bütünleşme üzerine alanyazın incelendiğinde ilkokul seviyesinde uygulanabilecek ve Türkçe olarak hazırlanmış yeterli sayıda ölçme aracı olmadığı görülmektedir. Bunun yanında bütünleşme kavramı, işbirlikli öğrenme içerisinde önemli bir değişken olarak kabul edilmektedir ve yöntemin başarısı üzerinde meydana getirdiği etkiyi, bütünleşme değişkeni üzerinden gerçekleştirdiği alanyazında ulaşılan bir sonuçtur. $\mathrm{Bu}$ araştırmada geliştirilen ölçeğim, gelecek araştırmalara kaynaklık edeceğine inanılmaktadır.

\section{Kaynaklar}

Aronson, E., Bridgeman, D. L. ve Geffner, R. (1978). The effects of a cooperative classroom structure on students' behavior and attitudes. Social Psychology of Education: Theory and Research, 257-272.

Battistich, V., Solomon, D. ve Delucchi, K. (1993). Interaction processes and student outcomes in cooperative learning groups. The Elementary School Journal, 94(1), 19-32.

Büyüköztürk, Ş. (2013). Sosyal bilimler için veri analizi el kitabı. Ankara: Pegem Akademi Yayıncilık.

Büyüköztürk, Ş., Çakmak, E. K., Akgün, Ö. E., Karadeniz, Ş. ve Demirel, F. (2014). Bilimsel araştırma yöntemleri. Ankara: Pegem Akademi.

Can, A. (2016). SPSS ile bilimsel araştırma sürecinde nicel veri analizi. Ankara: Pegem Akademi. 
YYÜ Eğitim Fakültesi Dergisi (YYU Journal of Education Faculty), 2020; 17(1):700-721, http://efdergi.yyu.edu.tr,

Carless, S. A. ve De Paola, C. (2000). The measurement of cohesion in work teams. Small group research, 31(1), 71-88.

Carron, A. V. (1982). Cohesiveness in sport groups: interpretations and considerations. Journal of Sport psychology, 4(2), 123-138.

Chang, A. ve Bordia, P. (2001). A multidimensional approach to the group cohesion-group performance relationship. Small Group Research, 32(4), 379-405.

Cohen, E. G. (1994). Restructuring the classroom: Conditions for productive small groups. Review of Educational Research, 64(1), 1-35.

Çokluk, Ö., Şekercioğlu, G. ve Büyüköztürk, Ş. (2012). Sosyal bilimler için çok değişkenli istatistik. Ankara: Pegem Akademi.

Dirlikli, M., Aydın, A. ve Akgün L. (2016). Cooperative learning in turkey: A content analysis of theses. Educational Sciences: Theory and Practice, 16(4):1251-1273.

Erbil, D. G. ve Kocabaş, A. (2018). Cooperative Learning as a Democratic Learning Method. Journal of Research in Childhood Education, 32(1), 81-93.

Festinger, L. (1950). Informal social communication. Psychological Review, 57(5), 271.

Festinger, L., Schachter, S. ve Back, K. (1950). Social pressures in informal groups; a study of human factors in housing community. Palo Alto, CA: Stanford University Press.

Gillies, R. (2004). The effects of communication training on teachers' and students' verbal behaviours during cooperative learning. International Journal of Educational Research, $41,257-279$.

Gross, N. ve Martin, W. E. (1952). On group cohesiveness. American Journal of Sociology, $57(6), 546-564$.

Hattie, J. (2009). Visible learning: A synthesis of over 800 meta-analyses relating to achievement. London: Routledge.

Hurley, A. E., Scandura, T. A., Schriesheim, C. A., Brannick, M. T., Seers, A., Vandenberg, R. J., ve Williams, L. J. (1997). Exploratory and confirmatory factor analysis: Guidelines, issues, and alternatives. Journal of Organizational Behavior: The International Journal of Industrial, Occupational and Organizational Psychology and Behavior, 18(6), 667683. 
Johnson, D. W. ve Johnson, R. T. (2008). Social Independence Theory and Cooperative Learning: The Teacher's Role. R. B. Gillies, A. F. Ashman, and J. Terwel (Ed.) The Teacher's Role in Implementing Cooperative Learning in the Classroom içinde (s. 9-37). New York: Springer.

Johnson, D. W., Johnson, R. T. ve Stanne, M. E. (2000). Cooperative learning methods: A meta-analysis. Minneapolis, MN: University of Minnesota Press.

Jöroskog, K. G. ve Sörböm, D. (1993). Lisrel 8: Structural Equation Modeling with the SimplisCommand Language. Lincolnwood: Scientific Software International Inc.

Kocabaş, A., Aşık, A., Karaşahin, İ., Erbil, D. G. ve Erdoğan, F. (2015). Türkiye'de işbirlikli öğrenme yönteminin uygulandığı tezlerin içerik analizi. VII. International Congress of Educational Research. Abstract (s. 175). Ankara: Pegem.

Kyndt, E., Raes, E., Lismont, B., Timmers, F., Cascallar, E. ve Dochy, F. (2013). A metaanalysis of the effects of face-to-face cooperative learning. Do recent studies falsify or verify earlier findings? Educational Research Review, 10, 133-149.

Marsh, H. W. ve Grayson, D. (1995). Latent variable models of multitrait-multimethod data. In R. Hoyle (Ed.), Structural equation modeling: Concepts, issues and applications (s. 177-198). Thousand Oaks, CA: Sage.

Martin, L. J., Carron, A. V., Eys, M. A. ve Loughead, T. M. (2012). Development of a cohesion inventory for children's sport teams. Group Dynamics: Theory, Research, and Practice, 16(1), 68.

Mattingly, R. M. ve van Sickle, R. L. (1991). Cooperative learning and achievement in social studies: Jigsaw II. Social Education 55(6), 392-395.

Mullen, B. ve Copper, C. (1994). The relation between group cohesiveness and performance: An integration. Psychological Bulletin, 115(2), 210.

Prien, K. O. (2001). The effects of cooperative learning, cohesion, and commitment on team performance. Dissertation Abstracts International Section A: Humanities and Social Sciences, 61(11-A), 4460.

Sargent, L. D. ve Sue-Chan, C. (2001). Does diversity affect group efficacy? The intervening role of cohesion and task interdependence. Small Group Research, 32(4), 426-450. 
Schumacker, R. E. ve Lomax, R. G. (1996). A beginner's guide to structural equation modeling. Mahwah, NJ: Lawrence Erlbaum Associates.

Sharan, Y. ve Shachar, C. (1988). Language and Learning in the Cooperative Classroom. New York: Springer-Verlag.

Sharan, Y. ve Sharan, S. (1990). Group investigation expands cooperative learning. Educational Leadership, 47(4), 17-21.

Sharan, Y. ve Sharan, S. (1992). Expanding cooperative learning through group investigation. New York: Teachers College Press.

Slavin, R. E. (1995). Cooperative Learning: Theory, Research, and Practice. Boston, MA: Allyn ve Bacon.

Slavin, R. E. (2015). Cooperative learning in elementary schools. Education 3-13, 43(1), 5-14. Sümer, N. (2000). Yapısal eşitlik modelleri. Türk Psikoloji Yazıları, 3 (6), 49-74.

Şencan, H. (2005). Sosyal ve davranışsal ölçümlerde güvenirlik ve geçerlilik. Ankara: Seçkin Yayıncilik.

Tarım, K. (2003). Kubaşık öğrenme yönteminin matematik öğretimindeki etkinliği ve kubaşık ögrenme yöntemine ilişkin bir meta analiz çalışması (Yayımlanmamış doktora tezi). Çukurova Üniversitesi, Adana.

Van den Bossche, P., Gijselaers, W. H., Segers, M. ve Kirschner, P. A. (2006). Social and cognitive factors driving teamwork in collaborative learning environments: Team learning beliefs and behaviors. Small Group Research, 37(5), 490-521.

Webb, N. M. (2008). Learning in Small Groups. T. L. Good (Ed.) In 21st Century Education: A Reference Handbook içinde (s. 203-211). Los Angeles, CA: Sage. 


\section{Bütünleşme Ölçeği}

Sosyal Bütünleşme Alt Boyutu

1) Kendimi grubuma ait hissederim.

1 Kesinlikle Katılmıyorum 2 Katılmıyorum 3 Ne Katılıyorum Ne Katılmıyorum 4 Katılıyorum 5 Kesinlikle Katılıyorum

2) Grubumu severim.

1 Kesinlikle Katılmıorum 2 Katılmıyorum 3 Ne Katılıyorum Ne Katılmıyorum 4 Katılıyorum 5 Kesinlikle Katıliyorum

3) Grup arkadaşlarımı benimle birlikte çalışmaları için davet ederim.

1 Kesinlikle Katılmıyorum 2 Katılmıyorum 3 Ne Katılıyorum Ne Katılmıyorum 4 Katılıyorum 5 Kesinlikle Katılıyorum

4) Grup arkadaşlarımla sık sık bir araya gelirim.

1 Kesinlikle Katılmıyorum 2 Katılmıyorum 3 Ne Katılıyorum Ne Katılmıyorum 4 Katılıyorum 5 Kesinlikle Katılıyorum

5) Grup arkadaşlarımla teneffüste vakit geçirmekten hoşlanırım.

1 Kesinlikle Katılmıyorum 2 Katılmıyorum 3 Ne Katılıyorum Ne Katılmıyorum 4 Katılıyorum 5 Kesinlikle Katılıyorum

6) Yaz tatilinde grup arkadaşlarımla görüşmeye devam etmek isterim.

1 Kesinlikle Katılmıyorum 2 Katılmıyorum 3 Ne Katılıyorum Ne Katılmıyorum 4 Katıliyorum 5 Kesinlikle Katılıyorum

7) Ders dışında da grup arkadaşlarımla birlikte hareket ederiz.

1 Kesinlikle Katılmıyorum 2 Katılmıyorum 3 Ne Katılıyorum Ne Katılmıyorum 4 Katılıyorum 5 Kesinlikle Katılıyorum

\section{Görev Bütünleşmesi Alt Boyutu}

8) Grup üyelerinin çalışma düzeylerinden mutluyum.

1 Kesinlikle Katılmıyorum 2 Katılmıyorum 3 Ne Katılıyorum Ne Katılmıyorum 4 Katılıyorum 5 Kesinlikle Katılıyorum

9) Grubum, kişisel başarımı artırmak için firsatlar sunar.

1 Kesinlikle Katılmıyorum 2 Katılmiyorum 3 Ne Katılıyorum Ne Katılmiyorum 4 Katıliyorum 5 Kesinlikle Katılıyorum

10) Grubumda, tüm üyeler aynı başarma inancına sahiptir.

1 Kesinlikle Katılmıyorum 2 Katılmıyorum 3 Ne Katılıyorum Ne Katılmıyorum 4 Katılıyorum 5 Kesinlikle Katılıyorum

11) Grup olarak bir arada çalışma yollarımızı severim.

1 Kesinlikle Katılmıyorum 2 Katılmıyorum 3 Ne Katılıyorum Ne Katılmıyorum 4 Katılıyorum 5 Kesinlikle Katılıyorum

12) Grubumuz birlikte hareket eder.

1 Kesinlikle Katılmıyorum 2 Katılmıyorum 3 Ne Katılıyorum Ne Katılmıyorum 4 Katılıyorum 5 Kesinlikle Katılıyorum

13) Grubum, bana becerilerimi geliştirmem için firsatlar sunar.

1 Kesinlikle Katılmıyorum 2 Katılmıyorum 3 Ne Katılıyorum Ne Katılmıyorum 4 Katılıyorum 5 Kesinlikle Katılıyorum

14) Grubumuz birlikte çalışırken iyi anlaşır.

1 Kesinlikle Katılmıyorum 2 Katılmıyorum 3 Ne Katılıyorum Ne Katılmıyorum 4 Katılıyorum 5 Kesinlikle Katılıyorum

15) Grup üyelerimiz birbirini başarı için cesaretlendirir.

1 Kesinlikle Katılmıyorum 2 Katılmıyorum 3 Ne Katılıyorum Ne Katılmıyorum 4 Katılıyorum 5 Kesinlikle Katılıyorum 


\section{Statement of Problem}

As a result of researches carried out the cooperative learning method for many years, it was found that this method has a positive impact on many psycho-social variables, especially academic achievement. Some different opinions were stated about the source of this positive impact. According to the model offered by Slavin (2015), cohesion has an important role in the development of academic achievement with the cooperative learning method. Different definitions for cohesion concept are introduced. An important one among these definitions is presented by Festinger. He stated (1950) that integration is the result of the efforts that all group members make for the group and that will be the force field ensure that the members remain in the group (Festinger, Schachter and Back, 1950). According to another definition, it is the group's resistance to destructive forces (Gross and Martin, 1952). According to the definition in a more modern period, it is a dynamic process that huddles the group together for common goals and objectives and ensures that the group remains united (Carron, 1982).

According to the reported studies on cohesion, it is found that cohesion is a combination of two concepts: task cohesion and social cohesion (Carless and DePaola, 2000; Van den Bossche et al., 2006). Mullen and Copper (1994) stated that task cohesion is the sharing in a group work to achieve a common goal. Social cohesion is the natural feelings such as friendship, love and proximity among group members.

The definition of this concept in the educational sciences is a process that group members help to other group members because they care about their own group (Slavin, 2015). This definition only deals with the social cohesion part of the cohesion concept. In the cooperative learning groups, students work together as small groups. Success is motivation that forces students come together. Although this is a personal success, they strictly motivated on success as a group. Because, the nature of this method states that individuals cannot be considered successful unless the group is successful as a whole (Slavin, 2015; Sharan and Sharan, 1992).

One of the most important factors for the success of the cooperative learning group is the group cohesion. The quality of interactions within the group is linked to the group's level of cohesion. Basically, group cohesion provides students to perform tasks to be done within the group in a better way. Because the student recognizes himself as a part of the group and also 
wishes each group member to be successful. According to the social cohesion theory; cooperative learning method and student success depends on group interactions (Battistich, Solomon and Delucchi, 1993). As a result of the researches, it is stated that the cohesion of the group members with their groups is very important for the success of the cooperative learning method (Sharan and Shachar, 1988; Sharan and Sharan, 1990; Slavin, 1995; Johnson and Johnson, 2008). While the group members working for a common purpose and reward, each student should be aware that the success of the group depends on his own success and therefore he should help other members for the success of the group also. In the cooperative learning process, while evaluating the group work, individual studies and the contribution of the individual to the group should also be considered. Additionally, in the success-oriented working process of the group, the group will work more effectively with the development of interpersonal and small-group skills. Therefore, only academic purposes and studies are not enough for the success of this method; in addition, interpersonal and small-group skills should be developed.

\section{Method}

This is a scale development study. At first, the opinions of 32 fourth grade primary school students about cohesion concept and the group study process were taken with a structured interview form. According to a literature survey, a review of the developed scales in other countries and the interviews with students 22 items were prepared in 5-point Likert type and reviewed by experts. The validity and reliability study of the scale was carried out with 242 fourth grade primary school students in İzmir. Cronbach's Alpha reliability coefficient, item discrimination values and item-total correlation values were calculated and evaluated for the reliability analysis. For validity analysis, exploratory (EFA) and confirmatory factor analyzes (CFA) were performed.

\section{Findings}

As a result of item analysis, 7 items with low loading values were excluded from the scale. The final form of the scale consists of two factors. The first factor called as task cohesion. This factor explains $34 \%$ of the total variance. The second factor called as social cohesion. This factor explains $9 \%$ of the total variance. Two factors explain $43 \%$ of the total variance. 
The developed two-factor structure confirmed with CFA. According to the CFA results (Table 2) $\chi^{2} /$ sd ratio is 1.555 . All results such as $\chi^{2} /$ sd ratio is lower than 3; RMSEA value is 0.048, which is below the 0.05, the perfect fit ratio; GFI and AGFI indexes are higher than 0.95; CFI and NNFI values are also higher than 0.95 , are indicative results that the developed scale displays a perfect fit (Jöreskog and Sörböm, 1993; Sümer, 2000; Çokluk, Şekercioğlu and Büyüköztürk, 2012).

Cronbach's Alpha reliability coefficient, item discrimination values and item-total correlation values were calculated and evaluated for the reliability analysis. A significant difference was found between the upper and lower 27\% groups for all items. According to the Cronbach's Alpha value, while the reliability value of the task cohesion factor is 0.788 , the social cohesion factor was calculated as 0.788 . The reliability of the whole scale was found to be 0.859 . The evaluation of the relationship between total scores and sub-factor scores revealed that there are positive and significant relationships $(\mathrm{p}<0.01)$ between social cohesion and task cohesion (0.610), between social cohesion and total score (0.880) and between task cohesion and total score (0.913).

\section{Discussion and Conclusion}

Cohesion is the main reason for the positive effect of cooperative learning on success and other psycho-social variables (Slavin, 2015). In this study, it is aimed to develop a cohesion scale for fourth grade primary school students and to better and more clearly explain the change in students by the cooperative learning method in further studies.

At the beginning of the scale development study, the fourth grade primary school students were asked questions about group work they performed by using a structured form. These questions were mainly based on cohesion concept; and the writing of the items was started by using these findings. The draft form of 22-item cohesion scale was designed in 5point Likert type. There were no negative items. The draft form was reviewed by five experts for content validity and some revisions were made according to the expert opinions. EFA and CFA analysis were used in the analysis of the scale data applied to 242 students. The two-factor structure was determined with the EFA and confirmed with CFA. The results obtained are similar to those obtained in the previous scale studies (Martin and et al., 2012; Carless and De Paola, 2000; Sargent and Sue Chan, 2001). Cronbach's Alpha reliability coefficient, item 
YYÜ Ĕ̈itim Fakültesi Dergisi (YYU Journal of Education Faculty), 2020; 17(1):700-721, http://efdergi.yyu.edu.tr,

discrimination values and item-total correlation values were calculated for the reliability analysis, and all of the findings indicated that the scale is reliable. Additionally, there is a positive and statistically significant relationship between the sub-dimensions of the scale and with the total score.

The cohesion scale consists of 15 items in 5-point Likert type. The scale has two subdimensions: social cohesion and task cohesion. It can be suggested student's higher scale score indicates a higher cohesion level. 